05,12

\title{
Магнитные свойства нанокристаллического материала на основе $\mathrm{Bi}_{2} \mathrm{Fe}_{4} \mathrm{O}_{9}$
}

\author{
(c) И.В. Бурьяненко ${ }^{1}$, В.Г. Семенов ${ }^{2,3}$, Н.А. Ломанова ${ }^{4, \text {, А.В. Осипов }}{ }^{5}$, М.П. Волков ${ }^{4}$, И.В. Плешаков ${ }^{4}$ \\ ${ }^{1}$ Санкт-Петербургский политехнический университет Петра Великого, \\ Санкт-Петербург, Россия \\ ${ }^{2}$ Санкт-Петербургский государственный университет, \\ Санкт-Петербург, Россия \\ ${ }^{3}$ Институт аналитического приборостроения РАН, \\ Санкт-Петербург, Россия \\ ${ }^{4}$ Физико-технический институт им. А.Ф. Иоффре РАН, \\ Санкт-Петербург, Россия \\ ${ }^{5}$ Институт химии силикатов им. И.В. Гребенщикова РАН, \\ Санкт-Петербург, Россия \\ 『 E-mail: natus@mail.ioffe.ru
}

Поступила в Редакцию 12 января 2022 г.

В окончательной редакции 12 января 2022 г.

Принята к публикации 13 января 2022 г.

Изучены магнитные характеристики нанокристаллического материала на основе феррита висмута $\mathrm{Bi}_{2} \mathrm{Fe}_{4} \mathrm{O}_{9}$, имеющего средний размер кристаллитов около $60 \pm 3 \mathrm{~nm}$. Полученный материал демонстрирует необычные магнитные свойства, проявляющиеся, в частности, в значительном увеличении величины намагниченности по сравнению с известной из литературы.

Ключевые слова: нанокристаллы, феррит висмута, муллит, магнитные свойства.

DOI: $10.21883 /$ FTT.2022.05.52334.274

\section{1. Введение}

Интерес к материалам на основе феррита висмута $\mathrm{Bi}_{2} \mathrm{Fe}_{4} \mathrm{O}_{9}$ с муллитоподобной структурой обусловлен возможностью их практического использования в магнитоэлектронике как мультиферроиков вблизи комнатной температуры [1,2], материалов для газовых сенсоров [3] и фотокатализаторов [4].

Соединение $\mathrm{Bi}_{2} \mathrm{Fe}_{4} \mathrm{O}_{9}$ имеет ромбическую элементарную ячейку (пр.гр. pbam) с параметрами $a=7.9 \AA$, $b=8.4 \AA$ и $c=6.0 \AA(Z=2)$, в которой атомы железа локализуются в кислородных октаэдрах $\mathrm{FeO}_{6}$ и тетраэдрах $\mathrm{FeO}_{4}$ [5]. Спины железа в октаэдрах взаимодействуют по ферромагнитному типу, а в тетраэдрах антиферромагнитно связаны между собой и спинами железа в октаэдрах [6,7]. Ниже комнатной температуры объемный $\mathrm{Bi}_{2} \mathrm{Fe}_{4} \mathrm{O}_{9}$ является антиферромагнетиком с температурой Нееля $T_{N}=237-265 \mathrm{~K}[7,8]$.

В керамических образцах отмечается наличие примесных фаз, которые могут влиять на магнитное поведение материала [8-10]. В работе [8] обнаружено, что для $\mathrm{Bi}_{2} \mathrm{Fe}_{4} \mathrm{O}_{9}$ характерно коллинеарное ферромагнитное (FM) и неколлинеарное плоское антиферромагнитное (AFM) упорядочение спинов. Показано, что появление отличной от нуля намагниченности (около $3 \mu_{\mathrm{B}} /$ unit) антиферромагнетика $\mathrm{Bi}_{2} \mathrm{Fe}_{4} \mathrm{O}_{9}$ может объясняться наличием вакансий в висмутовой подрешетке.

Метод растворного горения является эффективным для получения нанокристаллических ферритов различного состава, в том числе $\mathrm{Bi}_{2} \mathrm{Fe}_{4} \mathrm{O}_{9}$, при достаточно высокой температуре, поскольку быстрое протекание реакции горения не способствует рекристаллизационному росту частиц [11-22].

Нанокристаллические частицы $\mathrm{Bi}_{2} \mathrm{Fe}_{4} \mathrm{O}_{9}$ с размерами менее $60 \mathrm{~nm}$ имеют небольшой магнитный момент, возникновение которого связывается с состоянием вещества на поверхности. Во многих работах сообщается, что вблизи комнатной температуры намагниченность у нанокристаллических материалов на основе $\mathrm{Bi}_{2} \mathrm{Fe}_{4} \mathrm{O}_{9}$ может существовать, но она довольно мала $[1,4,7,22]$. (Некоторое ее повышение наблюдается у твердых растворов типа $\mathrm{Bi}_{2-x} \mathrm{~A}_{x} \mathrm{Fe}_{4} \mathrm{O}_{9}$ в связи с перераспределением ионов железа в структуре [23]).

Мёссбауэровские исследования состояния ионов железа в сложных оксидах, в том числе нанокристаллических, дают полезную информацию о механизмах их образования и особенностях магнитного поведения [1,7,12,13,15-17,24-27]. Данные таких экспериментов, представленные в работах $[1,7,17,27]$, продемонстрировали, что свойства наноматериалов на основе $\mathrm{Bi}_{2} \mathrm{Fe}_{4} \mathrm{O}_{9}$ могут заметно отличаться от свойств объемного вещества. В связи с этим, представляется целесообразным дальнейшее изучение факторов, позволяющих изменять магнитные характеристики нанокристаллических частиц $\mathrm{Bi}_{2} \mathrm{Fe}_{4} \mathrm{O}_{9}$.

Целью настоящей работы было исследование магнитных характеристик нанокристаллического материала на основе феррита висмута $\mathrm{Bi}_{2} \mathrm{Fe}_{4} \mathrm{O}_{9}$, полученного методом глицин-нитратного горения. 


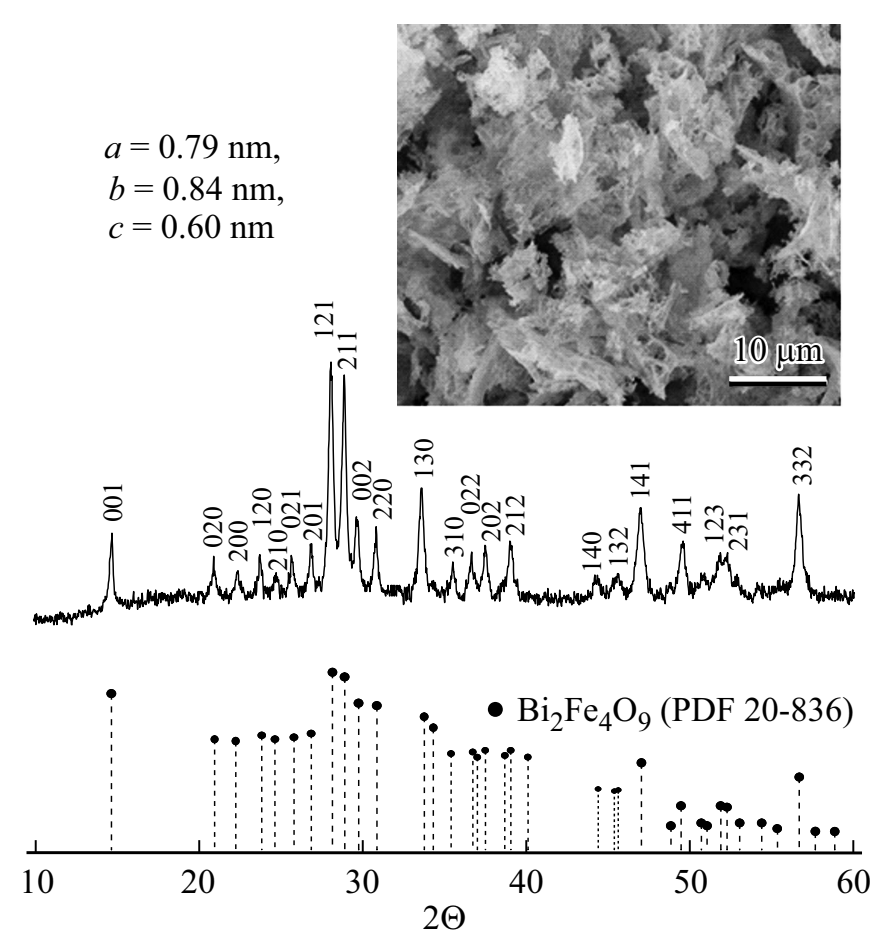

Рис. 1. Рентгеновская дифрактограмма материала на основе $\mathrm{Bi}_{2} \mathrm{Fe}_{4} \mathrm{O}_{9}$ (на вкладке SEM-изображение образца).

\section{2. Экспериментальная часть}

Материал синтезировался методом глицин-нитратного горения с использованием в качестве исходных реагентов нитрата висмута, нитрата железа и глицина. Отношение количества молей глицина $G$ и нитрат-ионов $N$ составляло $G / N=0.28$, что соответствовало реакции горения с 50\% недостатком глицина для потенциального понижения температуры горения и получения целевого продукта с наименьшим размером кристаллитов.

Продукт горения, представляющий порошок бурого цвета, последовательно термообрабатывался при температурах 350,550 и $650^{\circ} \mathrm{C}$ в течении $20 \mathrm{~min}$. После завершающей стадии синтеза при $650^{\circ} \mathrm{C}$ данные рентгенофазового анализа (дифрактометр XRD-7000 Shimadzu, $\mathrm{CK} \alpha$-излучение) показали отсутствие заметных количеств объемных примесных фаз (рис. 1) и параметры элементарной ячейки основной фазы соответствовали $\mathrm{Bi}_{2} \mathrm{Fe}_{4} \mathrm{O}_{9}$ (PDF 20-836). Средний размер кристаллитов целевого продукта, рассчитанный по формуле Шеррера, составляет $60 \pm 3 \mathrm{~nm}$.

Микроструктура и элементный состав полученного материала определялись методами сканирующей электронной микроскопии и элементного энергодисперсионного микроанализа (сканирующий электронный микроскоп FEI Quanta 200 с приставкой EDAX). Определено, что материал представлял собой пористые агрегаты частиц (рис. 1, вкладка). Среднее соотношение элементов в образце, составляло $\mathrm{Bi}: \mathrm{Fe}=2.04: 3.96$, т.е. в пределах погрешности метода соответствовало заданной стехиометрии.

Магнитные измерения проводились на вибрационном магнитометре системы PPMS (Quantum Design). Изучались зависимости удельной намагниченности $M$ от поля $H$ в диапазоне температур от гелиевых до превышающих комнатную, а также температурный ход $M$ при постоянном поле $H=200$ Oе в режимах FC (field cooling) и ZFC (zero field cooling).

Мёссбауэровское исследование образцов было выполнено на спектрометре WISSEL в геометрии на поглощение при комнатной температуре (источник ${ }^{57}$ Со в матрице родия, величины изомерных сдвигов IS приводятся относительно IS $\alpha$-Fe).

\section{3. Результаты магнитных исследований}

\section{1. Магнитометрия}

Петли намагничивания $\mathrm{Bi}_{2} \mathrm{Fe}_{4} \mathrm{O}_{9}$, полученные при разных температурах, показаны на рис. 2. Эти кривые имеют особенности, существенно отличающие их от соответствующих характеристик керамических, а также нанокристаллических образцов, синтезированных в различных условиях $[1,2,7,8]$. Прежде всего обращает на себя внимание то, что данный материал демонстрирует необычно высокую намагниченность, заметно превышающую значения, приведенные, например, в $[1,7]$ (см. табл. 1). Установить значение $M$ при насыщении невозможно, поскольку последнее, как видно из рис. 2, не достигается даже при очень больших $H$. При перемагничивании материала наблюдается гистерезис, особенно хорошо выраженный при низких температурах (табл. 1). На кривых $M(H)$ присутствует обычный для магнитоупорядоченных материалов излом, причем в интервале $-140<H<140 \mathrm{kOe}$ они сохраняют подобие вплоть до $T=400 \mathrm{~K}$.

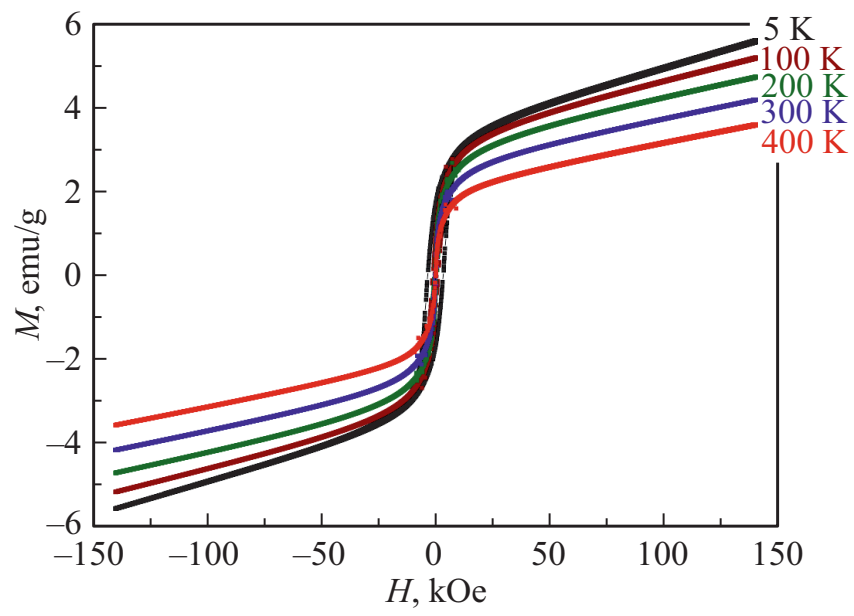

Рис. 2. Кривые намагничивания образца, измеренные при различных температурах. 


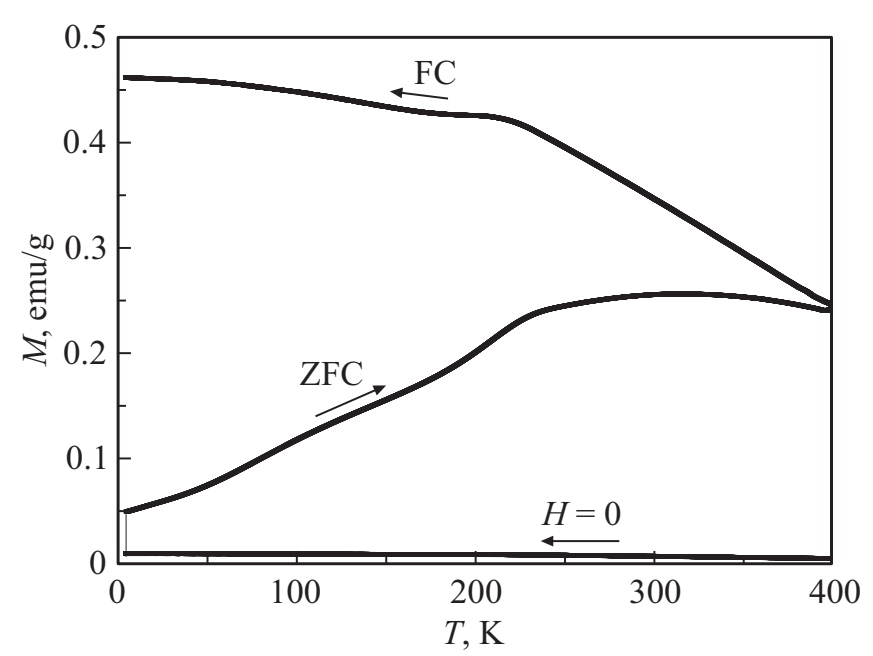

Рис. 3. Температурные зависимости FC/ZFC удельной намагниченности образца, измеренные при $H=200 \mathrm{Oe}$.

Результаты измерения $M(T)$ в $\mathrm{FC}$ и ZFC режимах показаны на рис. 3. В целом эти зависимости сходны с теми, которые наблюдаются в большинстве магнитных нанопорошках. Расхождение кривых происходит около $400 \mathrm{~K}$, характерные максимумы (при $T>200 \mathrm{~K}$ ) проявлены слабо и размыты. При этом следует отметить, что, по крайней мере на ZFC-кривой, можно определить наличие дополнительного максимума при $T \approx 100 \mathrm{~K}$.

\section{2. Мёссбауэровская спектроскопия}

Мёссбауэровский спектр, приведенный на рис. 4, показывает, что полученный материал при комнатной

Таблица 1. Магнитные характеристики образца

\begin{tabular}{|c|c|c|c|c|}
\hline \multirow{2}{*}{$\begin{array}{c}\text { Температура, } \\
\text { K }\end{array}$} & \multirow{2}{*}{$\begin{array}{l}H_{c}, \\
\mathrm{kOe}\end{array}$} & \multirow{2}{*}{$\begin{array}{c}M_{r}, \\
\mathrm{emu} / \mathrm{g}\end{array}$} & \multicolumn{2}{|c|}{$M, \mathrm{emu} / \mathrm{g}(20 \mathrm{kOe})$} \\
\hline & & & эксперимент * & литература** \\
\hline 5 & 3.5 & 1.65 & 3.14 & - \\
\hline 100 & 1.3 & 0.92 & 2.97 & - \\
\hline 200 & 0.54 & 0.54 & 2.76 & - \\
\hline 300 & 0.23 & 0.27 & 2.40 & $0.5[1] ; 1.1[7]$ \\
\hline 400 & 0.10 & 0.12 & 2.00 & - \\
\hline
\end{tabular}

Примечание.

* Экспериментальные данные для образца с размером кристаллитов $60 \mathrm{~nm}$;

** Данные для образцов с размером кристаллитов 60-70 nm.

Таблица 2. Параметры мёссбауэровского спектра

\begin{tabular}{l|c|c|c|c|c}
\hline Компонент & $\Gamma, \mathrm{mm} / \mathrm{s}$ & $I S, \mathrm{~mm} / \mathrm{s}$ & $Q S, \mathrm{~mm} / \mathrm{s}$ & $H_{\text {eff }}, \mathrm{T}$ & $\mathrm{A}, \%$ \\
\hline Doublet 1 & - & 0.24 & 0.99 & - & 39 \\
Doublet 2 & - & 0.36 & 0.42 & - & 41 \\
Sextet & 1.48 & 0.34 & 0.08 & 44.7 & 20 \\
& $0.35^{*}$ & $0.39^{*}$ & $-0.16^{*}$ & $51.2^{*}$ & -
\end{tabular}

Пр и ме ч ан и е. * Параметры $\alpha-\mathrm{Fe}_{2} \mathrm{O}_{3}[28]$. температуре парамагнитен. Основная часть спектра описывается двумя дублетами, параметры которых близки к известным из работ [17,27] параметрам соединения $\mathrm{Bi}_{2} \mathrm{Fe}_{4} \mathrm{O}_{9}$. Значения изомерного сдвига IS и квадрупольного расщепления $Q S=0.99$ и $0.42 \mathrm{~mm} / \mathrm{s}$ типичны для ионов $\mathrm{Fe}^{3+}$ в тетраэдрическом и октаэдрическом окружении, соответственно (табл. 2). На спектре также можно выделить слабо выраженный секстет, параметры которого соответствуют оксиду железа $\alpha-\mathrm{Fe}_{2} \mathrm{O}_{3}$, не зафиксированному методом рентгеновской дифрактометрии в виде объемной фазы. Отметим, что основной рефлекс (104) соединения $\alpha-\mathrm{Fe}_{2} \mathrm{O}_{3}$ (PDF 1-1053) может накладываться на рефлекс (130) соединения $\mathrm{Bi}_{2} \mathrm{Fe}_{4} \mathrm{O}_{9}$ (PDF 20-836), в связи с чем их было бы трудно различить рентгенографически.

\section{4. Обсуждение результатов}

Появление в образце фазы типа $\alpha-\mathrm{Fe}_{2} \mathrm{O}_{3}$, обнаруженной в мёссбауэровском эксперименте, может объясняться пониженной температурой горения смеси при недостатке органического топлива, что также предполагает наличие в образце рентгеноаморфного оксида висмута, который, как правило, локализуется на границах зерен. Некоторое уменьшение величины сверхтонкого поля $H_{e f f}=44 \mathrm{~T}\left(H_{e f f} \approx 51 \mathrm{~T}\right.$ для кристаллической фазы $)$ и большая ширина линии $\Gamma=1.48 \mathrm{~mm} / \mathrm{s}$ (у кристаллической фазы $\Gamma \sim 0.3 \mathrm{~mm} / \mathrm{s}$ ) показывает, что гематитоподобная фаза является нанодисперсной. Согласно [13,16], образовавшиеся при близких условиях синтеза малые железосодержащие кластеры могут быть локализованы в закрытых порах, на границах зерен, а также на поверхности нанокристаллов. В работах $[13,16,24]$ среди возможных механизмов, лежащих в основе сильного увеличения намагниченности подобных материалов, указывают присущее наночастицам влияние поверхности.

Величина $Q S$ свидетельствует о нарушении симметрии окружения иона железа. Возможно, что наличие $\alpha-\mathrm{Fe}_{2} \mathrm{O}_{3}$ в материалах на основе $\mathrm{Bi}_{2} \mathrm{Fe}_{4} \mathrm{O}_{9}$ в некоторых работах осталось незамеченным [27] в связи с более узким диапазоном измерения мёссбауэровского спектра. В $[17,20]$ сообщается, что в таких материалах может наблюдаться некоторое количество железосодержащих и обогащенных висмутом объемных примесных фаз.

Необычные магнитные свойства синтезированного нами материала, по всей вероятности, следует связать с существованием на поверхности нанокристаллов $\mathrm{Bi}_{2} \mathrm{Fe}_{4} \mathrm{O}_{9}$ подобного гематиту магнитоупорядоченного вещества. Большая намагниченность вряд ли могла бы быть объяснена только присутствием дополнительной фазы, точно соответствующей $\alpha$ - $\mathrm{Fe}_{2} \mathrm{O}_{3}-$ по магнитным характеристикам этот оксид в кристаллическом состоянии является антиферромагнетиком со слабым ферромагнетизмом, и его следовое количество в образце не могло бы дать существенного вклада в магнитный отклик. Изложенное выше указывает, однако, на то, 


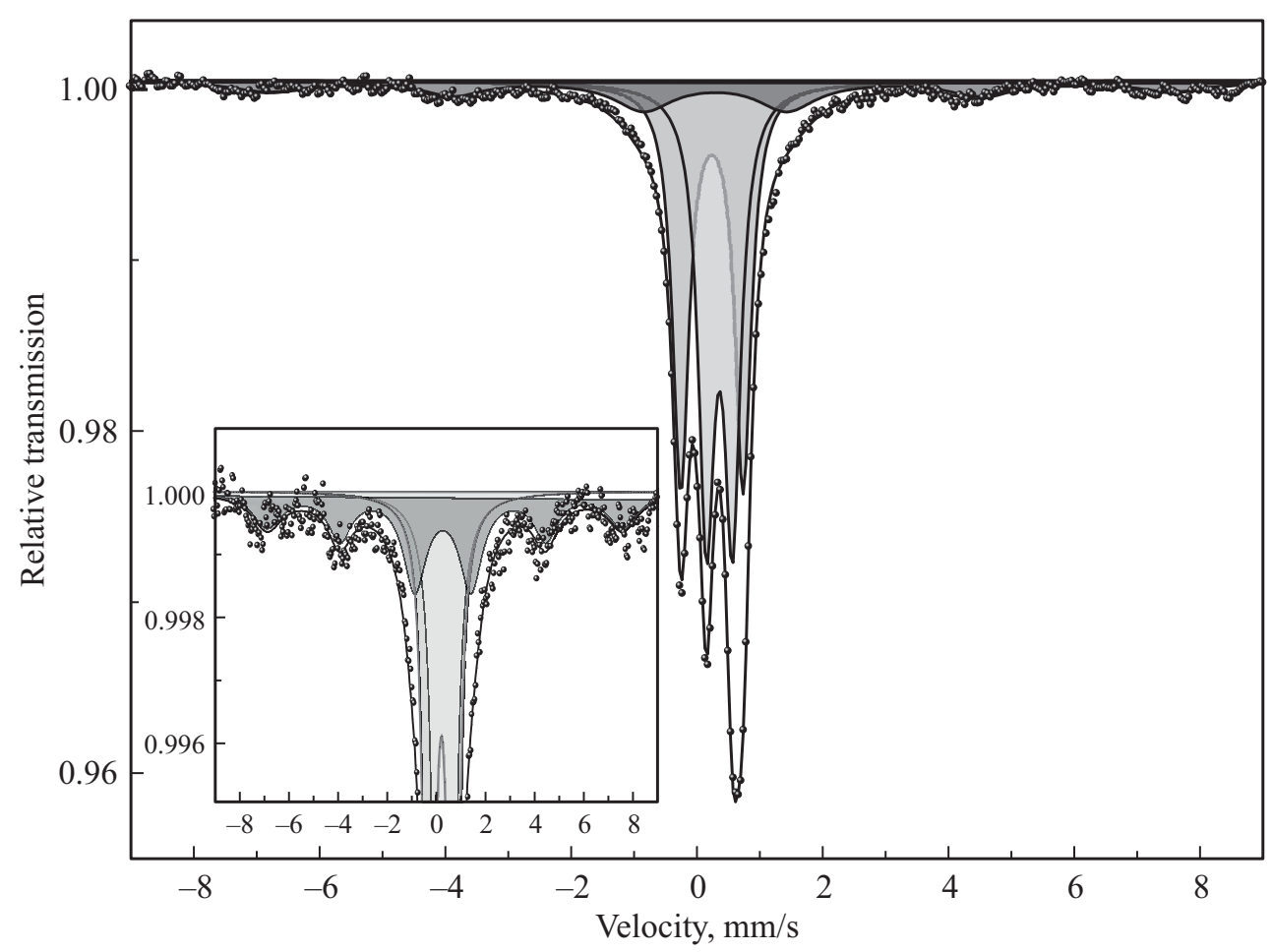

Рис. 4. Мёссбауэровский спектр материала на основе $\mathrm{Bi}_{2} \mathrm{Fe}_{4} \mathrm{O}_{9}$ (на вкладке увеличенная часть спектра).

что его структура сильно искажена. Появление значительной намагниченности заставляет предположить, что слабоферромагнитный порядок нарушен, и за счет изменения почти антипараллельной ориентации подрешеточных моментов у $\alpha-\mathrm{Fe}_{2} \mathrm{O}_{3}$ возникает большой суммарный момент. Взаимодействие с веществом основного состава в приповерхностной области может приводить к утолщению магнитного слоя и дополнительному увеличению полной намагниченности. Такая схема подтверждается монотонным ростом $M$ с увеличением $H-$ возможно, что разориентированные моменты поворачиваются в больших полях (рис. 2). При малых полях система ведет себя как суперпарамагнетик с несколькими магнитными фракциями, что можно заключить на основании данных, приведенных на рис. 3.

Качественно сходное поведение кривых намагничивания до $T=400 \mathrm{~K}$ (рис. 2) свидетельствует о сохранении магнитного порядка как минимум до этой температуры. В то же время мессбауэровский эксперимент показывает, что основное вещество в ядре нанокристаллитов при комнатной температуре находится в парамагнитном состоянии (данное утверждение согласуется с известными сведениями о температуре Нееля). Тем не менее, парамагнитный отклик, вклад которого (по оценке, выполненной для ионов $\mathrm{Fe}^{3+}$ с замороженным орбитальным моментом и полным моментом $J=5 / 2)$ при $T>260 \mathrm{~K}$ должен быть достаточно велик, не наблюдается (на такой эффект имеются косвенные указания и в других работах [1]). По всей вероятности, это может быть объяснено предположением о том, что магнитоупорядо- ченная оболочка, сформированная на границах частиц и состоящая как из гематитоподобной фазы, так и, возможно, из прилегающих к ней слоев с наведенным магнетизмом, имеет достаточно большую толщину и обеспечивает магнитную экранировку ядра.

\section{5. Заключение}

Методом глицин-нитратного горения синтезирован нанокристалилческий материал $\mathrm{Bi}_{2} \mathrm{Fe}_{4} \mathrm{O}_{9}$ со средним размером кристаллитов $60 \pm 3 \mathrm{~nm}$, обладающий значительно повышенной намагниченностью (по сравнению с известной из литературы), причем характерной особенностью этого вещества является по крайней мере частичное сохранение магнитоупроядоченного состояния до высоких температур $(400 \mathrm{~K})$. Его необычные магнитные свойства связываются, предположительно, с возникновением у нанокристаллов поверхностного слоя, обеспеченного особенностями синтеза и преимущественно ответственного за магнитные характеристики системы.

Результаты работы могут быть полезны при создании новых магнитных материалов для магнитоэлектроники.

\section{Благодарности}

Авторы благодарят В.В. Гусарова (ФТИ им. А.Ф. Иоффе) за обсуждение результатов и ценные замечания. 


\section{Конфликт интересов}

Авторы заявляют, что у них нет конфликта интересов.

\section{Список литературы}

[1] Z.M. Tian, S.L. Yuan, X.L. Wang, X.F. Zheng, S.Y. Yin, C.H. Wang, L. Liu. J. Appl. Phys. 106, 103912 (2009). http://dx.doi.org/10.1063/1.3259392

[2] X.H. Wu, J. Miao, Y. Zhao, X.B. Meng, X.G. Xu, S.G. Wang, Y. Jiang. Optoelectron. Adv. Mater. Rapid Commun. 7, 1-2, 116-120 (2013).

[3] J. Yang, J. Gao, P. Fu, Zh. Chen, Sh. Wang, L. Liu, Zh. Lin. Mater. Res. Express 6, 095083 (2019).

[4] Q. Zhang, W. Gong, J. Wang, X. Ning, Zh. Wang, X. Zhao, W. Ren, Zh. Zhang. J. Phys. Chem. C 115, 25241 (2011).

[5] Q. Zhang, P. Kong, H. Zhao, X. Shen, Y. Li, X. Li, J. Liu, C. Jin, R. Yu. High. Press. Res. 33, 745 (2013).

[6] Z. Pchelkina, S. Streltsov. Phys. Rev. B 88, 054424 (2013).

[7] S.A.N.H. Lavasani, O. Mirzaee, H. Shokrollahi, A.K. Moghadam, M. Salami. Ceram. Int. 43, 15, 12120 (2017).

[8] K. Jindal, Sh. Ameer, M. Tomar, P.K. Jha, V. Gupta. Materials Today: Proceed. 47, 8, 1637 (2021).

[9] M.N. Iliev, A.P. Litvinchuk, V.G. Hadjiev, M.M. Gospodinov, V. Skumryev, E. Ressouche. Phys. Rev. B 81, 024302 (2010).

[10] A.K. Singh, S.D. Kaushik, B. Kumar, P.K. Mishra, A. Venimadhav, V. Siruguri, S. Patnaik. Appl. Phys. Lett. 92, 132910 (2008).

[11] И.В. Плешаков, М.П. Волков, Н.А. Ломанова, Ю.И. Кузьмин, В.В. Гусаров. Письма в ЖТФ 46, 21, 25 (2020).

[12] K.D. Martinson, V.A. Ivanov, M.I. Chebanenko, V.V. Panchuk, V.G. Semenov, V.I. Popkov. Nanosyst. Phys. Chem. Math. 10, 6, 694 (2019).

[13] Н.А. Ломанова, М.В. Томкович, Д.П. Данилович, А.В. Осипов, В.В. Панчук, В.Г. Семенов, И.В. Плешаков, М.П. Волков, В.В. Гусаров. Неорган. материалы 56, 12, 1342 (2020).

[14] K.D. Martinson, V.I. Popkov. Nanosyst. Phys. Chem. Math. 12, 5, 634 (2021)урн.

[15] V.I. Popkov, K.D. Martinson, I.S. Kondrashkova, M.O. Enikeeva, V.N. Nevedomskiy, V.V. Panchuk, V.G. Semenov, M.P. Volkov, I.V. Pleshakov. J. Alloy. Compd. 859, ArtNo 157812 (2021).

[16] N.A. Lomanova, V.V. Panchuk, V.G. Semenov, I.V. Pleshakov, M.P. Volkov, V.V. Gusarov. Ferroelectrics 569, 1, 240 (2020).

[17] A. Panda, R. Govindaraj, K. Vinod, G. Amarendr. AIP Conf. Proceed. 1953, 120058 (2018).

[18] О.Н. Карпов, М.В. Томкович, Е.А. Тугова. Журн. общ. химии 88, 10, 1692 (2018).

[19] J. Zhao, T. Liu, Y. Xu, Y. He, W. Chen. Mater. Chem. Phys. 128, 388 (2011).

[20] E. Tugova, S. Yastrebov, O. Karpov, R. Smith. J. Cryst. Growth 467, 88 (2017).

[21] E.A. Tugova, O.N. Karpov. Rare Met. 40, 7, 1778 (2021).

[22] K.D. Martinson, V.A. Ivanov, M.I. Chebanenko, V.V. Panchuk, V.G. Semenov, V.I. Popkov. Nanosyst. Phys. Chem. Math. 10, 6, 694 (2019).
[23] Y.Y. Liang, J.X. Lei, X.X. Wang, L.G. Wang, C.M. Zhu. J. Mater. Sci.: Mater. Electron. 30, 1691 (2019).

[24] T.-J. Park, G.C. Papaefthymiou, A.J. Viescas, A.R. Moodenbaugh, S.S. Wong. Nano Lett. 7, 766 (2007).

[25] E.A. Tugova, A.A. Krasilin, V.V. Panchuk, V.G. Semenov, V.V. Gusarov. Ceram. Int. 46, 15, 24526 (2020).

[26] O.V. Proskurina, R.S. Abiev, D.P. Danilovich, V.V. Panchuk, V.G. Semenov, V.N. Nevedomsky, V.V. Gusarov. Chem. Eng. Proc. - Proc. Intensif. 143, 107598 (2019).

[27] A. Kirsch, M.M. Murshed, P. Gaczynski, K.-D. Becker, Th.M. Gesing. Z. Naturforsch. 71, 5, 447 (2016).

[28] I.S. Lyubutin, C.R. Lin, Yu.V. Korzhetskiy, T.V. Dmitrieva, R.K. Chiang. J. Appl. Phys. 106, 034311 (2009).

Редактор Т.Н. Василевская 